\title{
Hubungan Komunikasi Terhadap Kinerja Karyawan Pada PKBM Insan Karya Tangerang Selatan
}

\author{
${ }^{1}$ Feb Amni Hayati, Eko Susetyo \\ Dosen Fakultas Ekonomi Universitas Pamulang \\ ${ }^{1}$ Email :febamni@gmail.com
}

\begin{abstract}
ABSTRAK
Penelitian ini bertujuan untuk mengetahui Hubungan komunikasi terhadap kinerja karyawan pada PKBM Insan Karya - Tangerang Selatan.

Penelitian ini bersifat deskriftif yaitu metode yang dilakukan dengan mengumpulkan, mengklasifikasi, serta menginterprestasikan data yang berhubungan dengan masalah yang dihadapi. Populasi dalam penelitian ini adalah seluruh karyawan, metode pengumpulan data dalam penelitian ini adalah kuesioner, dan studi dokumentas, analisis data menggunakan metode deskriptif kuantitatif yaitu dengan analisis korelasi untuk mengukur hubungan komunikasi terhadap kinerja karyawan pada PKBM Insan Karya - Tangerang Selatan.

Melalui pengujian koefisien korelasi (r) diperoleh nilai sebesar 0,566, artinya keeratan hubungan komunikasi terhadap kinerja karyawan pada PKBM Insan Karya - Tangerang Selatan adalah 56,6\%. Kemudian dari pengujian koefisien determinasi diperoleh nilai $0,3237 \%$ artinya variabel bebas yakni kontribusi komunikasi $32,37 \%$ terhadap kinerja karyawan pada PKBM Insan Karya Tangerang Selatan.
\end{abstract}

Kata Kunci : Komunikasi, Kinerja Karyawan 


\section{PENDAHULUAN}

Salah satu bentuk penyelenggaraan pendidikan nasional melalui jalur pendidikan Nonformal adalah Pusat Kegiatan Belajar Masyarakat yang selanjutnya akan ditulis sebagai PKBM, yang diselenggarakan oleh masyarakat di setiap kabupaten/kota. PKBM adalah sebagai tempat bagi warga untuk memperoleh pengetahuan dan keterampilan dengan memanfaatkan sarana prasarana dan segala potensi yang ada di sekitar lingkungan kehidupan masyarakat dalam rangka untuk meningkatkan taraf hidupnya. Dikatakan sebagai pusat kegiatan belajar masyarakat, karena di dalamnya menyediakan berbagai macam jenis Pendidikan yang sesuai dengan kebutuhan masyarakat, seperti: Kejar Paket A, Kejar Paket B, Kejar Paket C, Kursuskursus, KBU, dan jenis pendidikan lainnya. Pada umumnya pengelola dan penyelenggara PKBM adalah masyarakat, tetapi juga difasilitasi oleh pemerintah (KEMENDIKBUD, melalui Subdin Pendidikan Luar Sekolah (PNF) di tingkat propinsi atau kabupaten/kota).

Sebagaimana diketahui bahwa PKBM adalah wadah berbagai kegiatan pembelajaran masyarakat yang diarahkan pada pemberdayaan potensi masyarakat untuk menggerakkan pembangunan di bidang sosial, ekonomi, dan budaya. PKBM dibentuk oleh masyarakat, milik masyarakat dan dikelola oleh masyarakat untuk memperluas pelayanan kebutuhan belajar masyarakat. Pembentukan PKBM dilakukan dengan memperhatikan sumber-sumber potensi yang terdapat pada daerah yang bersangkutan terutama jumlah kelompok sasaran dan jenis usaha/keterampilan yang secara ekonomi, sosial dan budaya dapat dikembangkan untuk meningkatkan kesejahteraan warga belajar khususnya dan warga masyarakat sekitarnya.

PKBM sebagai institusi atau lembaga adalah suatu kelompok yang menampung aspirasi masyarakat, baik yang mempunyai aturan secara tertulis maupun tidak tertulis, tumbuh dalam masyarakat serta bertujuan untuk mencapai tujuan bersama. Menurut Wursanto (2003:11), "institusi atau lembaga adalah suatu kelompok yang menampung aspirasi masyarakat, baik yang mempunyai aturan secara tertulis maupun tidak tertulis, tumbuh dalam masyarakat serta bertujuan untuk mencapai tujuan bersama". Sedangkan institusi atau lembaga swasta ialah lembaga yang dibentuk oleh masyarakat karena adanya motivasi atau dorongan tertentu yang didasarkan atas suatu peraturan perundang-undangan tanpa adanya paksaan dari pihak manapun. Institusi atau lembaga ini secara sadar dan ikhlas melakukan kegiatan untuk ikut serta memberikan pelayanan masyarakat dalam bidang tertentu sebagai upaya meningkatkan taraf kehidupan dan kesejahteraan masyarakat.

PKBM yang merupakan tindak lanjut dari gagasan Community Learning Center telah dikenal di Indonesia sejak tahun enam puluhan. Secara kelembagaan, perintisannya di Indonesia dengan nama PKBM baru dimulai pada tahun 1998 sejalan dengan upaya untuk memperluas kesempatan masyarakat memperoleh layanan pendidikan (Sudjana, 2003, 2). PKBM ini 
merupakan salah satu alternatif yang dipilih dan dijadikan sebagai ajang proses pemberdayaan masyarakat. Hal ini selaras dengan adanyapemikiran bahwa dengan melembagakan Pusat Kegiatan Belajar Masyarakat, maka akan banyak potensi yang dimiliki oleh masyarakat yang selama ini belum dikembangkan secara maks imal. PKBM diarahkan untuk dapatmengembangkan potensipotensi tersebut menjadi bermanfaat bagi kehidupannya. Agar mampu mengembangkan potensipotensi tersebut, maka diupayakan kegiatan pembelajaran yang diselenggarakan di PKBM bervariasi sesuai dengan kebutuhan masyarakat. Selain itu, PKBM sebagai basis pendidikan bagi masyarakat perlu dikembangkan secara komprehensip, fleksibel, dan beraneka ragam serta terbuka bagi semua kelompok usia dan anggota masyarakat sesuai dengan peranan, hasrat, kepentingan, dan kebutuhan belajar masyarakat. Oleh karena itu, jenis pendidikan yang diselenggarakan dalam PKBM juga beragam sesuai dengan kebutuhan Pendidikan dan pembelajaran masyarakat dimana PKBM tersebut dibentuk dan didirikan.

PKBM Insan Karya Tangerang Selatan adalah salah satu PKBM yang melayani kegiatan pembelajaran jalur non formal, yang berlokasi di Jalan Haji Saleh, Tangerang Selatan, dalam hal pengembangan PKBM baik peserta didik maupun pengajar atau tutor, dibutuhkan komunikasi yang baik, tepat guna dan tepat sasaran, baik komunikasi ke sesama pengajar atau tutor, komunikasi tutor kepada peserta didik maupun komunikasi tutor kepada masyarakat sekitar.

Menurut Himstreet dan Baty dalam Djoko Purwanto (2011:4) komunikasi adalah suatu proses pertukaran informasi antar individu melalui suatu sistem yang biasa (lazim), baik dengan simbol, sinyalsinyal, maupun tindakan atau prilaku. Komunikasi merupakan cara yang efektif untuk mempersatukan para tutor yang ada di dalam suatu organisasi. Ada dua model komunikasi dalam rangka meningkatkan kinerja dalam organisasi. Pertama, komunikasi koordinatif yaitu proses komunikasi yang berfungsi untuk menyatukan bagian-bagian dalam suatu organisasi. Kedua, komunikasi interaktif yaitu proses pertukaran informasi yang berjalan secara berkesinambungan, pertukaran pendapat dan sikap yang digunakan sebagai dasar penyesuaian antar bagian-bagian/divisi dalam organisasi maupun yang berada di luar organisasi, frekuensi dan intensitas komunikasi yang dilakukan juga dapat mempengaruhi hasil dari proses komunikasi tersebut. Komunikasi dapat dilihat dari berbagai saluran Komunikasi dari atas ke bawah, komunikasi dari bawah ke atas, komunikasi horizontal, komunikasi diagonal. Komunikasi juga harus dilakukan dengan baik agar semua pekerjaan dapat di selesaikan dengan baik dan tepat waktu. Baik komunikasi antara atasan kepada bawahan, komunikasi antar tutor atau antara tutor dengan atasan agar apa yang menjadi tujuan perusahaan dapat tercapai.

Berdasarkan observasi penulis terdapat beberapa kesalahan 
komunikasi di BKBM Insan Karya, proses komunikasi tidak berjalan dengan lancar seringkali terjadi kesalahan penyampaian pesan dari sesama tutor, cara penyampaian pesan kepada peserta didik dan orang tua kurang efektif, sehingga terjadi hubungan yang kurang baik diantara nya. Dalam hal ini komunikasi sangat berhubungan terhadap manajemen organisasi dalam menciptakan pola kerja yang konsisten terhadap situasi kerja yang nyaman. Jika komunikasi yang di lakukan oleh atasan kepada bawahannya tidak berjalan secara optimal tutor akan mengalami kesulitan memahami apa yang menjadi keinginan atasan sehingga kinerja yang di lakukan para tutor tidak terkontrol dengan baik. Bukan hanya komunikasi antara atasan dan bawahan saja yang berhubungan dengan kinerja tutor namun komunikasi yang dilakukan antara tutor dengan tutor yang lain juga masih belum berjalan dengan baik, masih ada tutor yang berkomunikasi dengan tutor lainnya tidak memberikan informasi yang jelas dan lengkap sehingga berhubungan terhadap sikap para tutor tersebut. Dengan kurang efektifnya komunikasi organisasi yang di lakukan baik dari atasan kepada bawahan atau antara tutor dengan tutor yang lainnya maka akan berhubungan terhadap kinerja tutor yang kurang efektif dan kinerjanya akan menjadi rendah. Berdasarkan dari observasi awal yang penulis lihat bahwa di PKBM Insan Karya Tangerang Selatan belum terjadi adanya komunikasi yang maksimal.

Kinerja merupakan hasil karya yang dicapai oleh individu yang disesuaikan dengan tugas dan peran yang dihubungkan dengan suatu ukuran nilai tertentu dari perusahaan dimana individu tersebut bekerja. Menurut Wibowo (2017:1) mengatakan kinerja itu berasal dari kata performance yang berarti pekerjaan atau prestasi kerja. Namun perlu pula dipahami bahwa kinerja itu bukan sekedar hasil pekerjaan atau prestasi kerja tetapi juga mencakup bagaimana proses pekerjaan itu berlangsung. Sedangkan menurut Moeheriono (2012:3) kinerja atau performance merupakan gambaran mengenai tingkat pencapaian pelaksanaan suatu program kegiatan atau kebijaksanaan dalam mewujudkan sasaran, tujuan, visi, dan misi organisasi yang dituangkan melalui perencanaan strategis suatu organisasi.

Berdasarkan observasi permasalahan - permasalahan yang terjadi terkait komunikasi dan kinerja tutor pada PKBM Insan Karya Tangerang Selatan belum maksimal diantara nya Komunikasi antara atasan dan bawahan masih belum berjalan secara optimal, Komunikasi antara tutor yang satu dengan tutor yang lain tidak berjalan dengan baik, Kinerja tutor kurang efektif dan Banyaknya tutor yang tidak paham SOP kesemuanya itu harus dilakukan pembenahan agar visi dan misi PKBM terlaksana dengan baik. Manfaat penelitian ini adalah untuk memberikan sumbang saran yang kiranya bermanfaat bagi PKBM Insan Karya - Tangerang Selatandan terus menerus mengkaji ulang strategi-strategi dalam meningkatkan kinerja tutor serta Sebagai masukan yang bermanfaat bagi rekan sejawat dan mahasiswa dalam bidang komunikasi organisasidalam memperluas dan mengembangkan ilmu pengetahuan dengan data yang diperoleh penulis 


\section{METODE PENELITIAN}

Penelitian ini dilaksanakan pada PKBM Insan Karya - Tangerang Selatan yang beralamat di Jl. Haji Saleh, No. 29, RT. 05. RW. 02, Pamulang, Tangerang Selatan, 14516.. Jenis penelitian ini adalah deskriptif kuantitatif, populasi 36 tutor, teknik pengambilan sample menggunakan sample jenuh yaitu seluruh populasi dijadikan sampel.

Metode analisis data menggunakan analisis deskriptif, adapun tahapan analisis yang dilakukan adalah analisis koefisien korelasi (R), analisis koefisien determinasi ( $R$ Square), pengujian hipotesis

\section{HASIL PENELITIAN}

\section{A. Pengujian Instrumen Penelitian.}

\section{Uji Validitas}

Tabel 4.1

Pengujian Validitas

\begin{tabular}{|c|c|c|c|c|}
\hline Pernyataan & R-Hitung Komunikasi & R-Hitung Kinerja & $\boldsymbol{R}$-Tabel & Keputusan \\
\hline 1 & 0,566 & 0,590 & 0,282 & Valid \\
\hline 2 & 0,753 & 0,596 & 0,282 & Valid \\
\hline 3 & 0,697 & 0,620 & 0,282 & Valid \\
\hline 4 & 0,347 & 0,440 & 0,282 & Valid \\
\hline 5 & 0,757 & 0,556 & 0,282 & Valid \\
\hline 6 & 0,699 & 0,607 & 0,282 & Valid \\
\hline 7 & 0,499 & 0,342 & 0,282 & Valid \\
\hline 8 & 0,783 & 0,605 & 0,282 & Valid \\
\hline 9 & 0,742 & 0,415 & 0,282 & Valid \\
\hline 10 & 0,489 & 0,419 & 0,282 & Valid \\
\hline 11 & 0,549 & 0,562 & 0,282 & Valid \\
\hline 12 & 0,690 & 0,458 & 0,282 & Valid \\
\hline 13 & 0,586 & 0,596 & 0,282 & Valid \\
\hline
\end{tabular}

Sumber: Data Primer (Diolah).

Berdasarkan data tabel di atas diperoleh nilai $R$-Hitung lebih besar dari 0,282, maka semua item kuesioner dinyatakan valid. Untuk itu kuesioner yang digunakan layak untuk diolah sebagai data penelitian.

\section{Uji Reliabilitas.}

Tabel 4.2

Hasil Uji Reliabilitas Variabel Independen dan Dependen

\begin{tabular}{|c|l|c|c|l|}
\hline No. & \multicolumn{1}{|c|}{ Variabel } & $\begin{array}{c}\text { Coeficient } \\
\text { Alpha }\end{array}$ & $\begin{array}{c}\text { Standar } \\
\text { Chronbach } \\
\text { Alpha }\end{array}$ & Keputusan \\
\hline 1 & Komunikasi $(\mathrm{X})$ & 0,657 & 0.60 & Reliabel \\
\hline 2 & Kinerja $(\mathrm{Y})$ & 0,780 & 0.60 & Reliabel \\
\hline
\end{tabular}

Sumber: Data Primer diolah.

Berdasarkan hasil pengujian pada tabel di atas, menunjukkan bahwa variabel Komunikasi (X) dan
Kinerja (Y) dinyatakan reliabel, hal itu dibuktikan dengan masing-masing variabel memiliki nilai coeficien 
Alpha lebih besar dari Chronbath Alpha 0,60.

\section{B. Analisis Verifikatif}

\section{Analisis Koefisien Korelasi}

Analisis korelasi dalam penelitian ini untuk mengetahui seberapa besar hubungan antara variabel bebas $(\mathrm{X})$ yaitu komunikasi dan variabel terikat (Y) yaitu kinerja tutor. Rumus yang digunakan untuk menghitung korelasi antara variabel bebas (X) dengan variiabel terikat (Y) adalah: Korelasi Product Moment sebagai berikut:

$$
\begin{aligned}
\mathbf{r}_{\mathbf{x y}} & =\frac{\mathbf{n}\left(\sum \mathbf{X Y}\right)-\left(\sum \mathbf{X} \sum \mathbf{Y}\right)}{\sqrt{\left\{\mathbf{n}\left(\sum \mathbf{X}^{\mathbf{2}}\right)-\left(\sum \mathbf{X}\right)^{2}\right\}\left\{\mathbf{n}\left(\sum \mathbf{Y}^{\mathbf{2}}\right)-\left(\sum \mathbf{Y}\right)^{2}\right\}}} \\
\mathbf{r}_{\mathbf{x y}} & =\frac{52805}{92,658,915} \\
\mathbf{r}_{\mathbf{x y}} & =\mathbf{0 , 5 6 9}
\end{aligned}
$$

Dari hasil analisis perhitungan menggunakan rumus koefisien korelasi pearson ada hubungan korelasi positif antara komunikasi organisasi dengan kinerja tutor yaitu sebesar rxy $=569$ yang termasuk kategori sedang Maka untuk mengetahui seberapa besar hubungan komunikasi organisasi terhadap kinerja tutor adalah dengan menggunakan koefisien determinasi.

\section{Analisis Koefisien Determinasi}

Setelah mengetahui nilai koefisien korelasi (rxy) antara variabel ( $\mathrm{x})$ dan variabel (y), selanjutnya dilakukan analisis koefisien determinasi.Tujuan analisis determinasi dalam penelitian ini adalah untuk mengetahui hubungan antara variabel lingkungan kerja dan variabel kinerja tutor dalam persen
(\%). Rumus yang digunakan dalam analsisis koefisien determinasi yaitu:

$$
\begin{array}{|l|}
\hline \mathrm{KD}=\mathrm{r}_{\mathrm{xy}}^{2} \times 100 \% \\
\hline \mathrm{R}_{\mathrm{xy}}=0,569 \\
\mathrm{KD}=(0,569)^{2} \times 100 \% \\
=32,37 \%
\end{array}
$$

Artinya terdapat hubungan antara variabel komunikasi organisasi dan variabel kinerja tutor sebesar $32,37 \%$ sedangkan sisanya $67,63 \%$ mempunyai hubungan dengan variabel lainnya.

\section{Uji Signifikasi}

Berdasarkan hasil perhitungan diatas, maka penuis melakukan pengujian hipotesa dengan cara membandingkan nilai t tabel dengan nilai $\mathrm{t}$ tabel ditentukan berdasarkan tingkat signifikasi yang digunakan dan derajat kebebasan yang besarnya tergantung dari jumlah sampel. Tingkat signifikan yang penulis gunakan sebesar 5\% $(0,05)$

Rumus nilai $\mathrm{t}$ hitung adalah sebagai berikut:

$$
\begin{gathered}
t_{\text {hitung }}=\frac{\mathbf{r}_{\mathrm{xy}} \sqrt{\mathbf{n - 2}}}{\sqrt{\mathbf{1 - \mathbf { r } _ { \mathrm { xy } } ^ { 2 }}}} \\
t_{\text {hitung }}=\frac{0,569 \sqrt{51-2}}{\sqrt{1-(0,569)^{2}}} \\
t_{\text {hitung }}=\frac{3,983}{0,6762} t_{\text {hitung }}=
\end{gathered}
$$

5,890

Dengan demikian, karena $\mathbf{t}_{\text {hitung }}$ lebih besar dari pada $\mathbf{t}_{\text {tabel }}(5,890>2,010)$, maka Ho ditolak dan Hi diterima, 
sehingga disimpulkan bahwa terdapat hubungan positif dan signifikan komunikasi organisasi terhadap kinerja tutor pada PKBM Insan Karya

- Tangerang Selatan.

\section{KESIMPULAN DAN SARAN}

\section{A. Kesimpulan}

1. Komunikasi di PKBM Insan Karya - Tangerang Selatan berdasarkan hasil sebaran kuesioner yang di ambil sampel sebanyak 51 responden yang menjawab sangat setuju $(33,18 \%)$, setuju $(40,87 \%)$, ragu-ragu $(21,71 \%)$, tidak setuju $(3,31 \%)$, sangat tidak setuju $\quad(0,90 \%)$. Jadi komunikasi yang terjadi pada PKBM Insan Karya Tangerang Selatan sudah cukup baik.

2. Kinerja di PKBM Insan Karya Tangerang Selatan berdasarkan hasil sebaran kuesioner yang di ambil sampel sebanyak 51 responden yang menjawab sangat setuju(24,28\%), setuju $(45,70 \%)$, ragu-ragu $(24,73 \%)$, tidak setuju $(4,97 \%)$, dan sangat tidak setuju (0.30\%). Jadi kinerja yang terjadi di PKBM Insan Karya - Tangerang Selatan sudah cukup baik.

3. Hubungan komunikasi terhadap kinerja tutor pada PKBM Insan Karya - Tangerang Selatan terdapat pengaruh yang signifikan antara komunikasi organisasi terhadap kinerja tutor PKBM Insan Karya Tangerang Selatan yakni terbukti dengan nilai korelasi sebesar $\quad(r=0,569) \quad$ atau hubungan nya sebesar $\left(\mathrm{KD}=\mathrm{r}^{2}\right.$ $=32,37 \%$ ).

\section{B. Saran}

Berdasarkan hasil penelitian dan uraian sebelumnya, maka penulis mengajukan beberapa saran dengan harapan dapat memberikan manfaat, yaitu:

1. Disarankan komunikasi yang bersangkutan dengan informasi mengenai lembaga harus di sampaikan kepada tutor agar kinerja tutor semakin meningkat.

2. Media penyampaian informasi yang ada di lembaga harus di tingkatkan lagi baik dari segi pemilihan media penyampaian ataupun tempat untuk menyampaikan informasi harus di perbanyak dan di permudah agar setiap tutor dapat mampu dengan mudah menjangkau media informasi yang ada.

3. Laporan pekerjaan tutor harusnya lebih cepat lagi di tanggapi oleh atasan agar kerja tutor dapat cepat di selesaikan dengan cepat, serta alat dan sarana yang terdapat di lembaga harus di lengkapi lagi untuk menunjang setiap pekerjaan agar tetap berjalan dengan lancar, dan atasan juga harus memberkan lebih banyak lagi motivasi untuk tutor agar tutor dapat bekerja dengan makin semangat sehingga tutor bisa bekerja lebih optimal.

\section{DAFTAR PUSTAKA}

Amstrong dan Baron, Manajemen dan Evaluasi Kinerja Karyawan. Penerbit Aswajaya Pressido, Yogyakarta, 2014.

Arikunto, Dasar-Dasar Statistik. Penerbit Erlangga, Jakarta, 2004.

Bambang, Manajemen Sumber Daya Manusia Edisi Revisi. Penerbit Bumi Aksara, Jakarta, 2002. 
Djoko Purwanto, "Komunikasi Bisnis",Edisi IV, Erlangga, Jakarta, 2011.

H. Edy Sutrisno, M.Si, “ Manajemen Sumber Daya Manusia" Cetakan ke-01, Kencana, Jakarta 2009.

F.X. Suwarto M.S., “ Manajemen Kinerja” Cetakan ke-01, Cahaya Atma Pustaka, Yogyakarta, 2014.

George Terry R, Manajemen Sumber Daya Manusia Edisi Revisi. Penerbit PT Bumi Aksara, Jakarta, 2007.

Hasibuan Malayu, Manajemen Sumber Daya Manusia Edisi Revisi. Penerbit PT Bumi Aksara, Jakarta, 2014.

Jhon Fiske, "Pengantar Ilmu Komunikasi" Cetakan ke-3, PT Rajagrafindo Persada, Jakarta 2014.
Mondy, Manajemen Sumber Daya Manusia Edisi Kedua, Penerbit Alfabeta, Bandung, 2012.

Rivai Veithzal, Manajemen Sumber Daya Manusia Untuk Perusahaan. PenerbitPT Raja Grafindo Persada, Jakarta, 2010.

Sugiyono, "Metode Penelitian Bisnis: Pendekatan kualitatif, kuantitatif dan R\&D" Cetakan ke-13, Alfabeta, Bandung, 2011.

Sunarsi, D. (2018). Pengaruh Gaya Kepemimpinan, Motivasi Dan Disiplin Kerja Terhadap Kinerja Pendidik Yayasan Marvin. Inovasi, 5(1), 1-18.

Sunarsi, D. (2017). Pengaruh Disiplin, Motivasi, Dan Kompetensi Terhadap Prestasi Belajar (Studi Kasus Pada Mahasiswa Universitas. 